\title{
Pitiose cutânea em eqüinos: 14 casos
}

\author{
Cutaneous pythiosis in horses: 14 cases
}

\section{Eliza Simone Viegas Sallis ${ }^{1}$ Daniela Isabel Brayer Pereira ${ }^{2}$ Margarida Buss Raffi $^{1}$}

\section{RESUMO}

\begin{abstract}
A pitiose cutânea é uma doença crônica que afeta preferencialmente eqüinos e, raramente, bovinos, caninos, felinos e seres humanos. É causada por Pythium insidiosum, um fungo aquático. São relatados quatorze casos de pitiose cutânea em eqüinos do municipio de Uruguaiana, Rio Grande do Sul. As lesões se localizam, principalmente na região distal dos membros pélvicos e caracterizam-se macroscopicamente por granulomas subcutâneos, ulcerados com exsudação sero-sanguinolenta. Microscopicamente há áreas irregulares de necrose circundadas por infiltrado inflamatório constituído por eosinófilos, neutrófilos, macrófagos e abundante tecido fibrovascular. São descritos e discutidos os métodos de diagnóstico, sinais clinicos, achados de necropsia, histopatologia, diagnóstico diferencial e tratamento
\end{abstract}

Palavras-chave: pitiose, dermatite, Pythium insidiosum, eqüino, micoses cutâneas.

\section{ABSTRACT}

Cutaneous pythiosis is a chronic condition that may be fatal if early therapy is not implemented. It affects mainly horses and rarely cattle, dogs, cats and human beings. It is caused by Pythium insidiosum, which infects wounds on the skin of ventral abdomen, distal limbs and head of animals which pasture and drink water in swamped land. This report includes fourteen cases of pythiosis in horses from Uruguaiana, in the state of Rio Grande do Sul, Brazil. Methods of diagnosis and treatment are described and discussed.

Key words: pythiosis, dermatitis, Pythium insidiosum, equine, cutaneous mycosis.

\section{INTRODUÇÃO}

A pitiose cutânea é uma enfermidade crônica, cosmopolita, de áreas temperadas, tropicais e subtropicais (CHAFFIN et al., 1995; MENDOZA et al., 1996). É causada por Pythium insidiosum, um fungo classificado no reino Stramenopila (ALEXOPOULOS et al., 1996) classe Oomycetes, família Pythiaceae (DE COCK et al., 1987; MENDOZA et al., 1996). É um microrganismo aquático que se caracteriza por formação de zoosporos biflagelados, procedentes de esporângios filamentosos, que são a forma de propagação do agente. Os zoosporos são liberados periodicamente em águas pantanosas e infectam eqüinos e outros mamíferos que freqüentam esses locais. Os zoosporos móveis são atraídos para o pêlo dos animais, penetram na pele através de lesões preexistentes, produzindo a enfermidade. Casos clínicos são observados durante todo o ano, mas a maioria coincide com épocas de maior precipitação pluviométrica, acometendo animais de todas as idades, sexo ou raças (MILLER \& CAMPBELL, 1982a).

Em eqüinos, $\boldsymbol{P}$. insidiosum causa lesões cutâneas, progressivas, granulomatosas e ulcerativas, localizadas nas porções baixas dos membros e na região ventral toracoabdominal (MILLER \& CAMPBELL, 1982a; SANTOS et al., 1987; MEIRELES et al., 1993; CHAFFIN et al., 1995; TABOSA et al., 1999). Há relatos de lesões nos pulmões, linfonodos (GOAD, 1984, MILLER \& CAMPBELL, 1984), intestinos (MORTON et al., 1991; PURCELL et al., 1994) e ossos (ALFARO \& MENDOZA, 1990). Lesões subcutâneas e gastrintestinais foram descritas em cães (MILLER et al., 1983; PATTON et al., 1996; RIET-CORREA et al., 1998; DYKSTRA et al., 1999; HELMAN \&

\footnotetext{
${ }^{1}$ Curso de Pós-graduação em Medicina Veterinária, área de concentração em Patologia Veterinária, Universidade Federal de Santa Maria (UFSM), 97105-900, Santa Maria-RS. E-mail: simone@pucrs.campus2.br. Autor para correspondência.

${ }^{2}$ Departamento de Clínica e Medicina Veterinária Preventiva, Faculdade de Zootecnia, Veterinária e Agronomia - FZVA/PUCRS E-mail: daniela@pucrs.campus2.br
} 
OLIVER, 1999). Dois casos de pitiose foram descritos em felinos (BISSONNETTE et al., 1991; THOMAS \& LEWIS, 2000) e dois em bovinos (MILLER et al., 1985; SANTURIO et al., 1998). A infecção por $\boldsymbol{P}$. insidiosum em seres humanos ocorre nas formas ocular, subcutânea e sistêmica (SATHAPATAYAVONGS et al., 1989; IMWIDTHAYA, 1995).

As lesões cutâneas em eqüinos caracterizam-se macroscopicamente por granulomas subcutâneos ulcerados, entrecortados por galerias ramificadas (trajetos fistulosos), preenchidas por material necrótico, amarelado, seco e friável ("kunkers") que se desprende facilmente do tecido fibrovascular circunjacente (SANTOS et al., 1987; CHAFFIN et al., 1995; MENDOZA et al., 1996). Microscopicamente, se evidenciam áreas eosinofílicas de necrose constituídas principalmente de eosinófilos viáveis e degenerados, que correspondem aos "kunkers" observados macroscopicamente. Na periferia dessas áreas, observam-se imagens negativas tubuliformes correspondentes às hifas de $\boldsymbol{P}$. insidiosum. Circundando os "kunkers" há infiltrado de eosinófilos, macrófagos, intensa proliferação de tecido fibrovascular e, ocasionalmente, células gigantes e reação de Splendore-Hoeppli (MEIRELES et al., 1993).

No Brasil, já foram relatados casos de pitiose cutânea em eqüinos no Rio Grande do Sul (SANTOS et al., 1987; MEIRELES et al., 1993), Mato Grosso e Mato Grosso do Sul (LEAL et al., 2001), Paraíba (TABOSA et al., 1999), Rio de Janeiro (SANAVRIA et al., 2000) e em bezerros do Pantanal matogrossense (SANTURIO et al., 1998).

Este trabalho descreve 14 casos de pitiose cutânea em eqüinos do município de Uruguaiana, RS, diagnosticados entre 1995 e 2000 . São descritos e discutidos os sinais clínicos, a epidemiologia, as lesões macro e microscópicas, os métodos de diagnóstico e o tratamento.

\section{MATERIAL E MÉTODOS}

O material desse estudo foi obtido de 10 biópsias e 4 necropsias de eqüinos submetidos ao Setor de Patologia Veterinária do CAMPUS II-da Pontifícia Universidade Católica do Rio Grande do Sul (PUCRS), em Uruguaiana, RS.

Para a realização do exame direto foram colhidas as áreas necróticas ("kunkers") da lesão, trituradas e clarificadas com hidróxido de potássio a 20\%. Para a cultura de $\boldsymbol{P}$. insidiosum, foram colhidos fragmentos do material necrótico, lavados em água destilada e semeados em caldo Sabouraud dextrose mantido em estufa a $37^{\circ} \mathrm{C}$ por $48 \mathrm{~h}$. Fragmentos representativos das lesões foram fixados em formol neutro a $10 \%$, posteriormente clivados, processados e incluídos em parafina e cortados com 5 micrômetros de espessura. As colorações empregadas foram a Hematoxilina e Eosina (HE) e Grocott. Após ter sido confirmado o diagnóstico de pitiose, os eqüinos receberam de 7 a 10 doses de imunoterápico, Pitiumvac, com intervalo de 7 dias.

\section{RESULTADOS E DISCUSSÃO}

A maioria dos eqüinos afetados era da raça Crioula, de ambos os sexos, com idades entre 3 e 11 anos. A evolução das lesões variou de 35 dias a vários meses. Os animais apresentaram emagrecimento progressivo e desenvolviam ulcerações associadas a abundante tecido de granulação na pele, com exsudação sero-sanguinolenta.

Todos os animais apresentavam lesões cutâneas localizadas, principalmente nas porções distais dos membros pélvicos, região metatarso-falangeana (Figura 1). Dois eqüinos apresentavam lesão na pele sobre o esterno. As dimensões das lesões variavam de 7 a $30 \mathrm{~cm}$ de diâmetro, com características granulomatosas, ulceradas, com bordas edemaciadas e irregulares, cobertas por exsudato sero-hemorrágico. Ao corte, havia abundante tecido conjuntivo fibroso de consistência firme e brancacento, entrecortado por galerias cheias de material necrótico amarelado e que

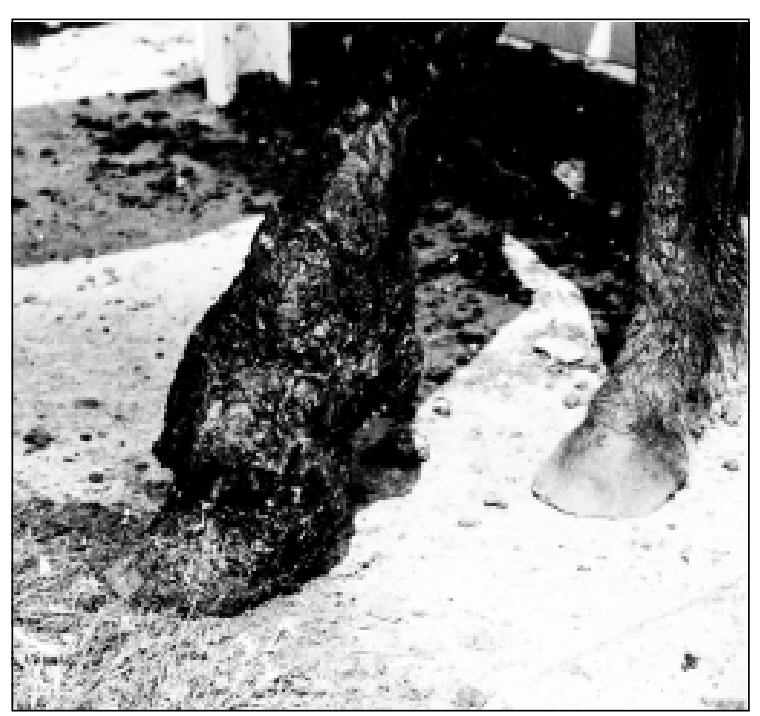

Figura 1 - Eqüino com lesão granulomatosa ulcerada na região metatarso falangeana esquerda. 
se desprendiam facilmente do tecido circunjacente ("kunkers"). No exame direto dos "kunkers", observouse um emaranhado de hifas de paredes finas e hialinas com raras septações e ramificações em ângulo reto. $\mathrm{O}$ material semeado em caldo Sabouraud mostrou crescimento de micélio algodonoso esbranquiçado. Ao exame micromorfológico, revelou as hifas raramente septadas, com ramificações em ângulo reto e sem estruturas reprodutivas, pois, nesse meio, o agente é estéril, características de $\boldsymbol{P}$. insidiosum.

No exame histológico, o aspecto das lesões foi semelhante em todos os casos. Observaram-se áreas irregulares e eosinofílicas de necrose associadas ocasionalmente, a imagens negativas tubuliformes de hifas fúngicas. Ao redor dessas áreas, havia infiltrado inflamatório constituído por eosinófilos, neutrófilos, macrófagos e marcada quantidade de tecido fibrovascular. Na coloração de Grocott, as hifas foram evidenciadas com estruturas ramificadas, ocasionalmente septadas, marrom-escuras, de paredes lisas e paralelas com tamanhos entre 6 e $10 \mu \mathrm{m}$ (Figura 2). O agente localizava-se principalmente nas margens das áreas de necrose.

Em todos os animais estudados nesse relato, as lesões observadas situavam-se nas porções distais dos membros, principalmente dos posteriores e na região ventral do abdômen. Essas áreas são mais afetadas por serem mais susceptíveis a lesões traumáticas e por ficar em contato com a água no momento em que os animais entram nos açudes, lagoas e banhados para beber água ou pastar a vegetação que brota nesses locais.

O curso clínico da doença varia de dias a meses e sua extensão depende do tempo de evolução das lesões, caracterizadas pelo crescimento exuberante de tecido fibrovascular, "kunkers", ulceração, exsudato sero-sanguinolento, prurido e emagrecimento progressivo dos animais. Essas lesões devem ser diferenciadas de habronemose cutânea causada pela deposição de larvas de nematódeos espirurídeos, Habronema (majus) microstoma, Habronema muscae e Draschia megastoma, cuja transmissão é feita por Musca domestica e Stomoxys calcitrans, com maior ocorrência no verão, regredindo nos meses frios do ano. As lesões ocorrem nas regiões do corpo do animal que mais freqüentemente atraem as moscas, como o canto medial do olho, pênis e prepúcio, além de feridas preexistentes nos membros (YAGER \& SCOTT, 1993). Macroscopicamente na habronemose há lesões circulares na pele de aproximadamente 5 a

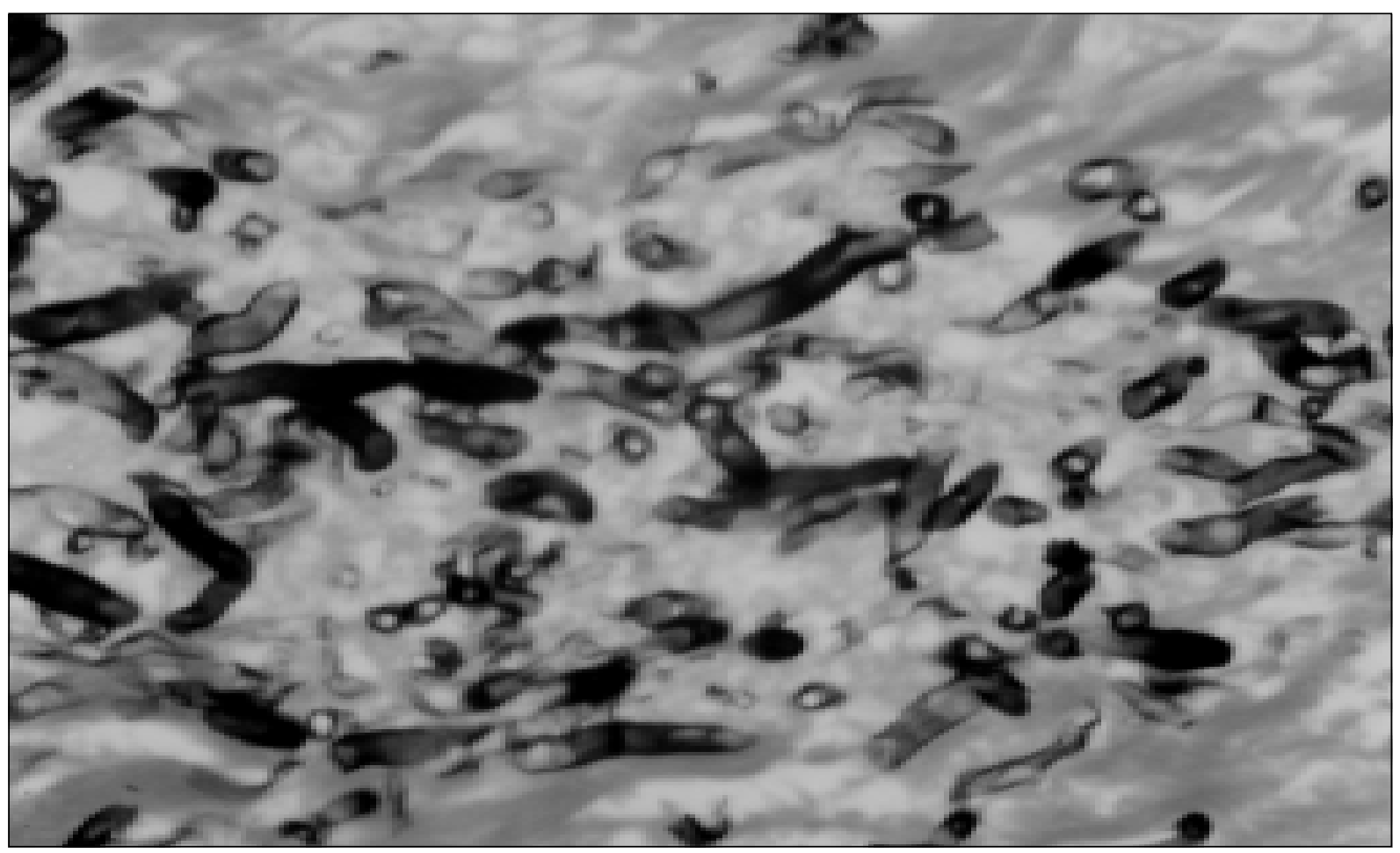

Figura 2 - Elementos filamentosos tubuliformes de Pythium insidiosum, com paredes paralelas e lisas e ramificações laterais. Grocott. Obj. 40.

Ciência Rural, v. 33, n. 5, set-out, 2003. 
$15 \mathrm{~cm}$ de diâmetro, com superfície ulcerada, ao corte há um tecido esbranquiçado com áreas focais brancoamareladas e ocasionalmente focos mineralizados. Essas áreas de necrose podem ser confundidas com os "kunkers", mas não formam estruturas ramificadas com tratos sinuosos características de pitiose. Microscopicamente há áreas multifocais de necrose, geralmente mineralizadas, com infiltrado inflamatório de eosinófilos, linfócitos, macrófagos, células epitelióides e gigantes, e proliferação de tecido conjuntivo fibrovascular. No centro dessas áreas de necrose, podem-se observar larvas ou restos de larvas de nematódeos, porém, em muitos casos, as larvas não são observadas. A superfície da lesão está coberta por um exsudato fibrinonecrótico. O ponto comum entre essas afecções é a ocorrência de lesões crônicas, com focos de necrose acompanhados por tecido de granulação; o achado de pseudo-hifas de $\boldsymbol{P}$. insidiosum ou imagens negativas deles na histopatologia permite a diferenciação entre pitiose e habronemose cutânea (MILLER \& CAMPBELL, 1984, SANTOS et al., 1987). Outras lesões que devem ser consideradas no diagnóstico diferencial, incluem o sarcóide eqüino e granulomas cutâneos como os causados por Conidiobolus spp e Basidiobolus haptosporus (MEIRELES et al., 1993). O sarcóide é o tumor de pele mais freqüente nesses animais e macroscopicamente pode ser confundido com pitiose, pois a distribuição das lesões ocorrem em locais similares, como região distal dos membros, parte ventral do tronco e cabeça. As lesões observadas podem ocorrer nas formas verrucosa, fibroblástica, nodular, oculta e mista. Na forma verrucosa, geralmente são lesões pequenas, sésseis ou pedunculadas, com aparência semelhante a couve-flor, na forma fibroblástica se apresentam como nódulos fibrosos bem circunscritos na derme, geralmente com ulceração da epiderme, predispondo a hemorragias e contaminação secundária, sendo a forma mais freqüente; o tipo nodular são massas firmes sob a pele normal e o oculto se apresenta como áreas circulares, alopécicas e áspera. Por meio do exame histológico, as lesões de sarcóide eqüino são facilmente diagnosticadas, evidenciando-se hiperplasia pseudoepiteliomatosa e na derme proliferação difusa de tecido conjuntivo fibroso e colágeno (MARTENS et al., 2000).

Para o tratamento de pitiose, recomendase remoção cirúrgica, quando a lesão é pequena (MILLER \& CAMPBELL, 1982a; MENDOZA et al., 1992). O uso de iodeto de potássio a $10 \%$ via intravenosa associado ao sulfato de cobre tópico resulta em cura parcial da lesão (CHAFFIN et al.,
1992; MEIRELES et al., 1993). Recentemente tem sido utilizado como alternativa de tratamento a imunoterapia associada à cirurgia, mas, apesar de apresentar eficácia de 50 a 83\% (MILLER, 1981; MENDOZA et al., 1992; MONTEIRO, 1999), há ocasiões em que as lesões não regridem totalmente. Isso foi observado em 8 eqüinos dos 14 que receberam o imunoterápico. A explicação para isso pode estar nos fatores individuais dos animais, como anergia em casos crônicos ou ausência de estimulação em casos agudos (MILLER \& CAMPBELL, 1982b).

A maioria dos materiais recebidos no Setor de Patologia da Faculdade de Zootecnia, Veterinária e Agronomia, PUCRS tinha diagnóstico presuntivo de habronemíase cutânea ou de sarcóide, mas pelo exame histológico com colorações especiais para o agente causal, exame direto, cultivo, isolamento e caracterização de $\boldsymbol{P}$. insidiosum, foi possível firmar o diagnóstico de pitiose. É recomendável realizar biópsia de lesões granulomatosas e ulcerativas na pele de eqüinos na fase inicial da doença, para possibilitar o tratamento correto.

\section{FONTE DE AQUISIÇÃO}

Imunoterápico para tratamento de pitiose eqüina: Pitium-vac - Laboratório de Pesquisas Micológicas (LAPEMI), Universidade Federal de Santa Maria (UFSM). Santa Maria-RS. 97105-900.

\section{REFERÊNCIAS BIBLIOGRÁFICAS}

ALEXOPOUlOS, C.J.; MIMS, C.W.; BLACKWELL, M. Phylum Oomycota. In: . Introductory mycology. 4.ed. New York : John Wiley \& Sons, 1996. Cap.23, p.683-737.

ALFARO, A.A.; MENDOZA, L. Four cases of equine bone lesions caused by Pythium insidiosum. Equine Vet J, v.22, n.4, p.295297, 1990.

BISSONNETTE, K.W. et al. Nasal and retrobulbar mass in a cat caused by Pythium insidiosum. J Med Vet Mycol, v.29, p.3944, 1991.

CHAFFIN, M.K.; SCHUMACHER, J.; McMULLAN, W.C. Cutaneous pythiosis in the horse. Vet Clin North Am Equine Pract, v.11, n.1, p.91-1103, 1995.

De COCK, W.A.E. et al. Pythium insidiosum sp. nov. the etiologic agent of Pythiosis. J Clin Microb, v.25, p.344-349, 1987.

DYKSTRA, M.J. et al. A description of cutaneous-subcutaneous pythiosis in fifteen dogs. Med Mycology, v.37, p.427-433, 1999.

GOAD, M.E.P. Pulmonary pythiosis in a horse. Vet Pathol, v.21, p.261-262, 1984.

HELMAN R.G.; OLIVER, J. Pythiosis of the digestive tract in 
dogs from Oklahoma. J Am Anim Hosp Assoc, v.35, n.2, p.111$114,1999$.

IMWIDTHAYA, P. Mycotic keratitis in Thailand. J Med Vet Mycol, v.33, p.81-82, 1995.

LEAL, A.B.M. et al. Pitiose eqüina no Pantanal brasileiro: aspectos clínico-patológicos de casos típicos e atípicos. Pesq Vet Bras, v.21, n.4, p.151-156, 2001.

MARTENS, A. et al. Histopathological characteristics of five clinical types of equine sarcoid. Research in Veterinary Science, v.69, p.295-300, 2000

MEIRELES, M.C.A. et al. Cutaneous pythiosis in horses from Brazil. Mycoses, v.36, p.139-142, 1993.

MENDOZA, L.; AJELLO, L.; McGINNIS, M.R. Infections caused by the oomycetous pathogen Pythium insidiosum. J Mycol Med, v.6, p.151-164, 1996.

MENDOZA, L.; VILlalobos, J.; CALlEJA, C.E. Evaluation of two vaccines for the treatment of pythiosis insidiosi in horses. Mycopathologia, v.119, p.89-95, 1992.

MILLER, R.I. Treatment of equine phycomycosis by immunotherapy and surgery. Aust Vet J, v. 57, p. 377-382, 1981.

MILLER, R.I.; CAMPBELL, R.S.F. Clinical observations on equine phycomicosis. Aust Vet J, v.58, p.221-226, 1982a.

MILLER, R.I.; CAMPBELL, R.S.F. Immunological studies on equine phycomicosis. Aust Vet J, v.58, p.227-231, 1982 b.

MILLER, R.I.; CAMPBELL, R.S.F. The comparative pathology of equine cutaneous phycomicosis. Vet Pathol, v.21, p.325-332, 1984.

MILlER, R.I.; OLCOTT, B.M.; ARCHER,M. Cutaneous pythiosis in beef calves. J Am Vet Med Assoc, v.186, n.9, p.984986, 1985.

MILLER, R.I.; QUALLS, C.W.; TURNWALD, G.H. Gastrointestinal phycomycosis in a dog. J Am Vet Med Ass, v.182, n.11, p.1245-1246, 1983.
MONTEIRO, A.B. Imunoterapia da pitiose eqüina: teste de eficácia de um imunobiológico e avaliação leucocitária em animais infectados naturalmente pelo Pythium insidiosum. 1999. 52f. Dissertação (Mestrado em Medicina Veterinária) Programa de Pós-graduação em Medicina Veterinária, Universidade Federal de Santa Maria.

MORTON, L.D. et al. Chronic eosinophilic enteritis attributed to Pythium sp in a horse. Vet Pathol, v.28, p.542-544, 1991

PATTON, C.S. et al. Esophagitis due to Pythium insidiosum infection in two dogs. J Vet Internal Med, v.10, n.3, p. 139-142, 1996.

PURCELL, K.L. et al. Jejunal obstruction caused by a Pythium insidiosum granuloma in a mare. J Am Vet Med Assoc, v.205, n.2, p.337-339, 1994

RIET-CORREA, F. et al. Doenças diagnosticadas no Laboratório Regional de Diagnóstico. In: Boletim do Laboratório Regional de Diagnóstico-UFPel. Pelotas: UFPel, 1998. 55p.

SANAVRIA, A. et al. Pitiose em eqüinos: Relato de cinco casos no Estado do Rio de Janeiro. R Bras Med Vet, v.22, n.4, p. 170173,2000 .

SANTOS, M.N. et al. Pitiose cutânea em eqüinos no Rio Grande do Sul. Pesq Vet Bras, v.7, n.3, p.57-61, 1987.

SANTURIO, J.M. et al. Cutaneous pythiosis insidiosi in calves from the Pantanal region of Brazil. Mycopathologia, v.141, p.123-125, 1998

SATHAPATAYAVONGS, B. et al. Human pythiosis associated with thalassemia hemoglobinopathy syndrome. J Infect Dis, v.159, n.2, p.274-280, 1989.

TABOSA, I.M. et al. Pitiose cutânea em eqüídeos no semi-árido da Paraíba. Arq Bras Med Vet Zootec, v.51, p.27-30, 1999.

THOMAS, R.; LEWIS, D. Pythiosis. Selecciones Veterinarias, v.8, n.3, p.313-319, 2000.

YAGER, J.A.; SCOTT, D.W. The skin and appendages. In: JUBB, K.V.F.; KENNEDY, P.C.; PALMER, R.N. Pathology of domestic animals. 4.ed. San Diego : Academic, 1993. V.1. Cap.5, p.692-693. 